\title{
A Markovian-QFD Approach in Addressing the Changing Priorities in Customer Needs
}

\author{
Mehdi Rajabi Asadabadi \\ Published in Journal of Quality and Reliability Management
}

DOI: https://doi.org/10.1108/IJQRM-07-2014-0091

\begin{abstract}
The overall objective of this paper is to address the problem of changing customer needs (CNs) in the quality function deployment (QFD) model. There are several papers attempting to employ various tools and techniques such as the analytic network process (ANP) and analytic hierarchy process (AHP) to find the accurate relations between the product requirements (PRs) and CNs. There are also few papers applying a Markov chain to determine a pattern of the relations in QFD. The less studied problem is about changes in the priorities of the CNs during the improvement process not only the relations. This paper connects a Markov chain to the QFD model to find a pattern for changing CNs and consequently the PRs. By applying a Markov chain, QFD becomes strengthened to receive, evaluate, and predict the future of CNs and be used independent from frequent meetings with customers. Applying a Markov chain for QFD creates an integrated approach to find a reasonable pattern for the priorities of CNs to be used instead of the initial ones while the QFD approach takes the inner and outer relations between all of the elements into account. It is realized that the new model can be applied independent of the initial CNs.
\end{abstract}

Key words: QFD; Markov Chains; ANP; AHP

\section{1- Introduction}

One of the most important characteristics dealing with the quality function deployment (QFD) method is the problem of constant changes (Ozdağoğlu \& Salum, 2009). Customers easily change the product brands when they don't see their needs fulfilled (Asadabadi, 2014), so the products have to be improved to match the customer needs (CNs). The improvement objectives need to be identified and prioritized, but it is not easy (Rika, 2014). QFD, as a tool to find the priority of a set of objective elements based on the priority of the CNs, is applied in strategic decisions of companies (Yahia, 2010). It acts as a framework in the process of translation of the CNs into the product requirements (PRs) (Andronikidis et al., 2009). Finding the CNs accurately (Raharjo et al., 2007) is a key in reaching a higher level of customer satisfaction (Delice \& Güngör, 2009).

Since QFD starts by obtaining the CNs (Raharjo et al., 2008; Raharjo et al., 2011), there should be an emphasis on accuracy of obtaining them. The problem is customer priorities are not very stable and they may change before the products are ready for the market (Asadabadi, 2014). On the other hand, the cost of manufacturing the products which don't match the customers' desires can be dramatically high. The changes in the CNs can be significant and applying a methodology to predict the CNs is essential (Shen et al., 2001; Wu et al., 2005; Shieh and Wu, 2009). This is a less studied problem which requires more investigations. The statistical models are not capable of finding the exact future of the CNs, but since the application of Markov chains is well-recognized in modeling the real world processes, it is of interest to examine the sufficiency of a Markov chain to track the changing priorities of the CNs. This study proposes a stochastic-QFD approach in which a Markov chain models the changing priorities of the CNs. In the proposed model, the inner and outer relations between the elements of QFD are observed to improve the translation process of the priority of the CNs into the PRs.

This paper contributes the knowledge by employing a Markov chain to receive, evaluate, and model the changing priorities of the CNs of QFD. A Markov chain is placed at the entrance of the QFD approach in order to develop it to a model capable of dealing with changing priorities of the CNs. The remainder of this paper is organized as follows. After this, some previous investigations on the QFD method, the analytic network process (ANP), analytic hierarchy process (AHP), and Markov chains are studied. Then, the methodology explaining the process of attaching 
a Markov chain to the QFD model is proposed. Following that, the applicability of the methodology is examined through an example. This research ends by a brief discussion and a conclusion.

\section{2- Literature review}

\subsection{QFD and its extensions}

QFD, as an approach to relate several sets of elements and address some complicated operational decisions, is widely used all over the world (Ginn \& Zairi, 2005). It is an efficient tool applied in product improvement processes (Yahia, 2010). It is the only tool which explicitly translates the CNs into the PRs (Sullivan, 1986; Yahia, 2010; Kuijt et al., 2009). The main concern of designing and developing a product is to fulfill the CNs (Kutschenreiter, 2013) and QFD as a translator of the CNs to the PRs can be significantly beneficial (Iqbal et al., 2014) to reach the highest possible level of the customer satisfaction (Ayag et al., 2013). The House of Quality as the main tool of the QFD approach is applied to find the relations between two sets of elements and prioritize a set of elements (e.g., PRs) based on another set (e.g., CNs) (Dey et al., 2012). The HOQ demonstrates the relations between the CNs (WHATs) and PRs (HOWs) in a matrix style chart (Hauster \& Clausing, 1988). As Lin and Pekkarinen (2011) expose, the HOQ includes six phases: "identification of customer requirements (WHATs), translation of customer requirements into service design characteristics (HOWs), determining the relationship between WHATs and HOWs, finding the relationships between the various service design characteristics, and designing the target values."

Various techniques, such as the AHP and ANP, are being employed to strengthen the capabilities of QFD (Yahia, 2010). The AHP as a structured technique is widely applied to deal with the multi-criteria decision making (MCDM) problems. The AHP represents a complex decision making problem in a simple hierarchy. It is applied in the HOQ to facilitate the process of determining relations between its elements (Kamvysi et al., 2010). By applying the AHP, all the determining factors of a complex decision making problem are organized to simplify the problem (Saaty, 1990). "The power built into AHP is comparative judgment principles. Based on the hierarchy, the principle of comparative judgments can be applied to determine the relative importance of criteria through the pair-wise comparisons. Hence, judgments are made based on the best information available considering the decision maker's inputs, their intuition and knowledge about the subject, and their experiences" (Yahia, 2010). Saaty (1986) introduces a consistency index to decide on validation of the comparisons, and determines where to accept or reject the comparisons result. The threshold value of consistency ratio (CR) is determined as 0.1 (Saaty, 1990). "The inconsistency of a matrix with all its pairwise comparisons can be interestingly captured by a single number, $\lambda_{\max }-n$, so this is enough to find out about the consistency of a matrix" (Saaty, 1986). Consistency index of a matrix is computed as: $C I=\frac{\lambda_{\max }-n}{n-1}$ and the perfect consistency happens where this index is equal to zero. If consistency index is less than 10 percent of a random matrix, the judgments are accepted; otherwise the comparisons have to be improved $\left(C R=\frac{C I}{R I}<0.1\right)$. RI amounts for order 3 and 4 are 0.52 and 0.89 (Saaty, 1986).

The AHP is not capable of taking the interdependencies between the elements into considerations. To consider the inner relations between the elements the ANP was developed (Steiner et al., 2011). Traditional QFD approach assumes no interdependencies among the elements (Lin et al., 2010) while in the ANP-QFD method, the ANP is applied to make the internal relations among the CNs and PRs observable (Büyüközkan \& Berkol, 2011). The ANP can be widely used for various purposes (Lin et al., 2010; Kamvysi et al., 2010; Andronikidis et al., 2009; Saaty, 1999). To do the pairwise comparisons, Saaty (1999) introduces a scale: "In making paired comparisons of homogeneous elements, ratios are estimated by using a "1 to 9 fundamental scales" of absolute numbers to compare two alternatives, with respect to an attribute" (Saaty, 1999), where the score of 1 indicates that both elements are equally important and 9 represents the extreme importance of an element in compare to the other element. The comparison matrix must be reciprocal. This means $a_{i j}=1 / a_{i j}$; "where $a_{i j}$ denotes the importance of the element " $i$ " in comparison with the element " $j$ ", and the relations are preserved in the numbers $w_{i}$ and $w_{j}$ and forming the ratio $w_{i} / w_{j}$, a single number between 1 and 9 is assigned to represent the ratio $w_{i} / w_{j}$. The absolute numbers from the scale is an approximation to the ratio $w_{i} / w_{j}$ " (Saaty, 1999). The ANP has to be used in a multicriteria decision making process because the traditional approaches are not able to take the internal relations into

To cite this document: Mehdi Rajabi Asadabadi, (2016) "A Markovian-QFD approach in addressing the changing priorities of the customer needs", International Journal of Quality \& Reliability Management, Vol. 33 Issue: 8, pp.1062-1075, https://doi.org/10.1108/IJQRM-07-20140091 
account (Saaty, 1999). The ANP relaxes the assumption of considering a hierarchy in analyzing the effects of the elements on each other. It lets all the elements affect each other where the influences are sensible.

Partovi (2001) quantifies the strategic service vision of an organization by applying the ANP in combination with the AHP. The AHP is employed in that study to find the intense between the row and column variable while the ANP is applied to deal with the interdependencies of the elements in columns (Partovi 2001). In 2006, again, an approach applying the ANP and AHP is applied by Partovi (2006). This time, the integration of the ANP and AHP is used in QFD to address the facility location problem. Next year, in 2007, an analytical technique for the selection process is investigated by Partovi (2007). In 2009, a combination of the AHP and ANP is investigated by Yang et al. (2009) to construct a performance evaluation model. They apply the combination of the AHP and ANP to create a better weighting basis. Wong et al. (2008) applied the AHP and ANP to find the interdependencies between the elements of system intelligence. The ANP-QFD approach has been widely employed in the previous studies; Kuijit (2009) focuses on the PRs of QFD in designing hand tools based on the customer preferences. Karsak et al. (2002) apply ANP-QFD in combination with the goal programing. Delice \& Güngör (2009) apply Kano Model for categorizing the CNs of the ANP-QFD. Kamvysi et al. (2010) focus on finding a remedy for failures in finding the correct priorities of the CNs. Andronikidis et al. (2009) deal with the problem of quick shifts in the CNs in service quality management. Ho et al. (2011) employ an ANP-QFD approach to come up with a sourcing solution.

Recently, some researchers have started developing the QFD method to create a less time consuming tool (Blitz QFD or modern QFD). The modern QFD is to convert the CNs into discrete elements (Baramichai et al., 2007) and then to find the product specifications by applying "engineer-friendly" tools (Mazure, 2008). In modern QFD, customer desires are in need of further analysis and evaluations to be acceptable by product developers (Zultner, 2005). Additionally, applying several matrices in the traditional approach becomes optional and focusing on a small number of the CNs is recommended (Mazure, 2008) to make the approach less time-consuming (Zultner, 1995).

QFD should be applied to encourage reaching beyond the stated needs by customers (Mazur, 2008). Considering the previous studies strengthening the QFD method, the important issue of changing CNs seems to be left only with few studies (Asadabadi, 2014). Raharjo et al. (2011) expose a change in the CNs priorities since the moment that they are obtained and applied to find the PRs priorities until the moment the product is sent to the market. They model the dynamics of the AHP by applying a forecasting technique. The correct recognition of the CNs priorities is critical; "In most cases, the reason of failure has not been a lack of technological capability of the firm, but an incorrect understanding of real customer needs and demands" (Steiner et al., 2011). According to Shen et al. (2001): "since CNs are changing, the future customer needs must be found to keep an organization with long-term efficiency. Sometimes these changes are predictable or are following a specific trend." On the other hand, customers are not always able to provide a clear expression of what they really want (Mazure, 2008). Furthermore, even if they are able to provide the deciders with a clear expression, gathering data frequently seems to be really cost and time consuming. Therefore, a methodology is developed to find the priority of the CNs independent of the initial priority.

\subsection{Markov Chains}

The efficiency of Markov chains in addressing conditional status has been investigated previously (Cheng et al., 2012). Over the last few decades, Markov chains are widely applied in various branches of knowledge e.g., from "turmoil in stock markets" (Castellano \& Scaccia, 2014) to reliability and maintenance (Gowid et al., 2014). Markov chains employ transition matrices to move from one state to another one (Saibeni, 2010). In Markov chains model, the probability of transitioning from one state to another one is defined as transition probability (Liu et al., 2011). The arrays of the transition matrix are the probabilities of moving to a state, given the current state. Liu et al. (2011) formulize and present a summary of the process of Markov chains model: "

$P\left(X_{n+1}=Y_{1} ; \ldots ; X_{n+m}=Y_{m} \mid X_{0}=Z_{0} ; \ldots ; X_{n}=Z_{n}\right)=$

$P\left(X_{n+m}=Y_{m} \mid X_{0}=Z_{0} ; \ldots ; X_{n+m-1}=Y_{m-1}\right) \ldots=$

$P\left(X_{n+1}=Y_{1} \mid X_{n}=Z_{n}\right) P\left(X_{n+2}=Y_{2} \mid X_{n+1}=Z_{n+1}\right) \ldots$

$P\left(X_{n+m}=Y_{m} \mid X_{n+m-1}=Z_{m-1}\right) ”$

Quantitative techniques and tools such as Markov chains can be applied to strengthen QFD (Andronikidis et al., 2009). According to $\mathrm{Wu}$ and shieh (2008) there are some advantages in applying a Markov chain for the QFD

To cite this document: Mehdi Rajabi Asadabadi, (2016) "A Markovian-QFD approach in addressing the changing priorities of the customer needs", International Journal of Quality \& Reliability Management, Vol. 33 Issue: 8, pp.1062-1075, https://doi.org/10.1108/IJQRM-07-20140091 
method; "when the decision makers do not have enough experiences or historical data, using probabilities to determine the relationships between customer requirements and technical measures as well as the importance of technical measures provide another alternative objectively in terms of expected values."

This study proposes a Markovian ANP-QFD approach which may efficiently handle the changes in customer needs. The Markov chains have been applied previously to develop the QFD method (Wu \& Shieh, 2008). The proposed model by Wu and Shieh (2008) does not take the internal relations of QFD into account. Furthermore, it applies a Markov chain to determine the relations between the elements of QFD, while this paper attempts to employ a Markov chain to determine a pattern for changing priorities of the CNs. The Markov chain in the proposed method is attached to the QFD method to provide it with an adjusted list of the priorities of the CNs.

\section{3- Methodology}

There are two frameworks previously used to develop the ANP-QFD method. One is applying the supermatrix introduced by Saaty and the other one is formed based on the logical concept of the supermatrix, but without involving the whole supermatrix in calculations (Karsak et al., 2002). The second approach is summarized in following few steps.

1-Identifying a prioritized list of the CNs

A list of the CNs with their priorities is obtained through some interviews and meetings with customers. The data may also be adjusted by decision makers based on their experience and intuition. The results are normalized and placed in a single column matrix $\left(W_{1}\right)$.

2-Identifying the PRs

The PRs are obtained in some meetings with the engineers and designers of the product development process. The data may also be accompanied by the inputs from the cross functional team. A cross functional team "consists of members from marketing, sales, $R \& D$, engineering, design, manufacturing and production, procurement, quality, service, etc." (Mazur, 2008)

3-Finding the interrelationships among the $\mathrm{CNs}$

This can be achieved by asking simple questions, e.g., "what is the relative importance of $\mathrm{i}^{\text {th }}$ customer need when compared to $j^{\text {th }}$ customer need" (Karsak et al., 2002)? CNs are compared to each other with respect to each CN in separate tables and the resulted importance weights build the columns of the relevant matrix $\left(W_{3}\right)$.

4-Determining the relations between the PRs and CNs

For acquiring this matrix, the intense of the relations among the PRs are evaluated and compared with respect to each CN. So if there are, e.g., 'n' CNs, 'n' tables are needed where in each table the PRs are compared with respect to one of the CNs. The importance weights of the PRs with respect to each $\mathrm{CN}$ are computed and moved to a specific column for that $\mathrm{CN}$ in a new matrix $\left(W_{2}\right)$.

5-Determining the interrelations among the PRs

An approach similar to step three is followed to obtain the inner dependencies among the PRs and the resulted importance weights build $W_{4}$.

Following the above steps, the supermatrix discussed and solved by Thomas Saaty (Saaty, 1999) is possible to build. The super matrix is shown below (Karsak et al., 2002).

$W=\begin{aligned} & \text { Goal Goal } \\ & \text { CNS } \\ & P R s\end{aligned}\left[\begin{array}{ccc}0 & 0 & 0 \\ W_{1} & W_{3} & 0 \\ 0 & W_{2} & W_{4}\end{array}\right]$ Matrix 1

To cite this document: Mehdi Rajabi Asadabadi, (2016) "A Markovian-QFD approach in addressing the changing priorities of the customer needs", International Journal of Quality \& Reliability Management, Vol. 33 Issue: 8, pp.1062-1075, https://doi.org/10.1108/IJQRM-07-20140091 
6-Finding $W_{A N P}$

$W_{A N P}=\left[W_{4} \times W_{2}\right] \times\left[W_{3} \times W_{1}\right]$ Eq. (1)

$W_{4}$ represents the relations among the PRs and $W_{2}$ the relations between the PRs and CNs, so the first part of the Eq. (1), $W_{4} \times W_{2}$, results in a matrix representing the relations between the PRs and CNs considering the internal relations. The second part of the Eq. (1), $W_{3} \times W_{1}$, represents the priorities of the CNs considering the interrelations among them. The result of multiplying the first part by the second part is the priority of the PRs considering all the relations and interrelations between the elements which is shown by $W_{A N P} . W_{1}$ is based on the initial priorities of the CNs, but as discussed previously, they are expected to change. The customer preferences change by time which means this matrix needs further evaluations.

$W_{1}=\left[\begin{array}{c}s_{1} \\ s_{2} \\ : \\ s_{n}\end{array}\right]$ Matrix 2

To expose the problem, assuming that at time zero $s_{i}$ is greater than $s_{j}$ which means, e.g., the average of customers are selecting $S_{i}\left(i^{\text {th }} \mathrm{CN}\right)$ rather than $S_{j}\left(j^{\text {th }} \mathrm{CN}\right)$, it is possible that $s_{i}$ becomes smaller than $s_{j}$ during the developing process of the product. When customers are buying or a company is selling the products in discrete times this approach is as follows. A set of times: $\mathrm{T}=\left\{t_{0}, t_{1} \ldots, t_{m}\right\}$ exists. Following that, a set of states $\mathrm{S}=\left\{s_{1}, s_{2} \ldots, s_{n}\right\}$ is defined. Then, $p_{i j}$ represents the probability of moving from $s_{i}$ to $s_{j}$, (changing the priority from $i^{\text {th }} \mathrm{CN}$ to $j^{\text {th }} \mathrm{CN}$ ). The probabilities in transition matrix are computed based on the historical data of customers' behaviours and reactions. These transition probabilities build the transition matrix.

$P=\frac{s_{1}}{\quad}\left[\begin{array}{cccc}s_{1} & s_{2} & \ldots & s_{n} \\ p_{11} & p_{12} & \ldots & p_{1 n} \\ p_{n} & \vdots & \ddots & \vdots \\ p_{21} & \vdots & \ddots & \vdots \\ p_{n 1} & \ldots & \ldots & p_{n n}\end{array}\right]$ Matrix 3

The first row presents the probabilities of changing from the first $\mathrm{CN}$ (first state) to the first (which means no changes in the preference), second, third..., and $\mathrm{n}^{\text {th }} \mathrm{CN}$ (state). The state after each step depends on the current state. As an example, the probability of being at state four at $t_{2}$, given state two as the current state (at $t_{0}$ ), is as follows.

$P\left(X_{t_{2}}=s_{4} \mid X_{t_{0}}=s_{2}\right)=p_{24}^{(2)}=p_{21} p_{14}+p_{22} p_{24}+\cdots+p_{2 n} p_{n 4} \quad$ Eq. (2)

A more generalized formula for being at state $\mathrm{j}$ given state $\mathrm{i}$ as the current state after two transitions is presented below.

$p_{i j}^{(2)}=\sum_{h=1}^{n} p_{i h} p_{h j} \quad$ Eq. (3)

By raising matrix $\mathrm{P}$ (the transition matrix) to the second power, $\mathrm{p}_{24}^{(2)}$ is found equal to the array at second row and $4^{\text {th }}$ column. In general, in matrix $\mathrm{P}^{\mathrm{k}}, \mathrm{p}_{\mathrm{ij}}^{(\mathrm{k})}$ (the probability of moving from state $\mathrm{i}$ to $\mathrm{j}$ after $\mathrm{k}$ steps) is the same as the array placed at $\mathrm{i}^{\text {th }}$ row and $\mathrm{j}^{\text {th }}$ column:

$P^{k}=\begin{array}{r}s_{1} \\ s_{2} \\ \vdots \\ s_{n}\end{array}\left[\begin{array}{cccc}s_{11}^{(k)} & s_{2} & \ldots & p_{n} \\ p_{12}^{(k)} & \ldots & p_{1 n}^{(k)} \\ p_{21}^{(k)} & \vdots & \ddots & \vdots \\ \vdots & \ddots & \ddots & \vdots \\ p_{n 1}^{(k)} & \ldots & \ldots & p_{n n}^{(k)}\end{array}\right]$ Matrix 4

Now, the input matrix of ANP-QFD, $W_{1}$, is adjusted by multiplying its transposed matrix by the transition matrix as follows $\left(W_{1}^{(i)}\right.$ represents the priorities of the CNs after i step(s)).

To cite this document: Mehdi Rajabi Asadabadi, (2016) "A Markovian-QFD approach in addressing the changing priorities of the customer needs", International Journal of Quality \& Reliability Management, Vol. 33 Issue: 8, pp.1062-1075, https://doi.org/10.1108/IJQRM-07-20140091 
$W_{1}^{(0)^{T}}=W_{1}^{T} I, W_{1}^{(1)^{T}}=W_{1}^{T} P^{1}, \ldots, W_{1}^{(i)^{T}}=W_{1}^{T} P^{i} \quad$ Eq. (4)

In a more general form:

$W_{1}^{(k)^{T}}=W_{1}^{T} P^{k}, \quad \forall k=0,1, \ldots, \infty \quad$ Eq. (5)

Following the above process, the priorities of the PRs are obtained as below.

$W_{A N P}^{(k)}=\left[W_{4} \times W_{2}\right] \times\left[W_{3} \times W_{1}^{(k)}\right]$ Eq. (6)

So finally $W_{A N P}^{(k)}$ is computed. In matrix $P$, the convergence shows up after few times self-multiplying. This creates a pattern. Although the matrix doesn't change after that, but it doesn't mean that customers do not change their priorities anymore. They are still changing their priorities, but only a pattern, which determines the final proportional priorities of CNs, is seen. This pattern saves time and makes the methodology applicable considering the rapid changes in markets. Since the previous assumption of selling products in discrete times seems rare in real cases, the resulted pattern of the priorities of the $\mathrm{CNs}$, which is interestingly resulted independent of the initial priorities of the CNs $\left(W_{1}\right)$ (see the next section) is applied rather than a series of CNs priorities to feed the model and find the priorities of the PRs in order to create a time saving methodology to fit the need of market in applying rapid tools.

\section{4-An example}

Gazar Pump Co. is a well-reputed manufacturer of floating electro-pumps located in Toos Industrial Town in Iran. The company is manufacturing centrifugal-water-well pumps. These centrifugal pumps are used to draw water up from deep wells and semi deep wells. The customer needs for the pumps are recognized to be the performance, reliability, serviceability, and cost of maintenance of the pumps where the important parameters are: the applied process and technology, used raw material, tolerances, and consumption of the engine. The normalized prioritization matrix of the CNs is $W_{1}$ which is obtained through some interviews and meetings with the customers (refer to steps of the methodology). Since four CNs and four PRs are recognized, 12 tables are required for the pairwise comparisons. The importance weights of each table contribute in building the matrices. Based on the methodology, three matrices, $W_{2}, W_{3}$, and $W_{4}$, are built. $W_{2}$ is built by moving the importance eigenvectors of the tables representing the relations among the PRs with respect to the CNs, such as table one, to a single matrix. After that, $W_{3}$ is built with the last columns of tables such as table 2, and finally the weights in tables such as table three are used to build $W_{4}$.

The below abbreviations are used throughout the example: the performance: Perf, reliability: Rel, serviceability: Serv, cost of maintenance: CoM, process and technology: Pro \& Tech (P\&T), used raw materials: Used RM, tolerances: Tolerances (Toler), consumption of the pumps: Consumption (Cons), and importance eigenvector: Weights

$$
W_{1}=\begin{aligned}
& \text { Perf } \\
& \text { Rel } \\
& \text { Serv } \\
& \text { Noises }
\end{aligned}\left[\begin{array}{l}
0.667 \\
0.033 \\
0.200 \\
0.100
\end{array}\right]
$$

\begin{tabular}{|c|c|c|c|c|c|}
\hline Table 1- & $\begin{array}{l}\text { With respect to the } \\
\text { reliability }\end{array}$ & Pro \& Tech & Used RM & Tolerances & Weights \\
\hline & Pro \& Tech & 1 & 5 & 3 & 0.648 \\
\hline & Used RM & $1 / 5$ & 1 & $1 / 2$ & 0.122 \\
\hline & Tolerances & $1 / 3$ & 2 & 1 & 0.230 \\
\hline & & $\lambda_{\max }=3.0004$ & $C I=0.002$, & $C R=0.004$ & \\
\hline Table $2-\mathrm{V}$ & th respect to the & Perf & Serv & CoM & Weights \\
\hline
\end{tabular}

To cite this document: Mehdi Rajabi Asadabadi, (2016) "A Markovian-QFD approach in addressing the changing priorities of the customer needs", International Journal of Quality \& Reliability Management, Vol. 33 Issue: 8, pp.1062-1075, https://doi.org/10.1108/IJQRM-07-20140091 


\begin{tabular}{|c|c|c|c|c|c|}
\hline Performance & & & & & \\
\hline Perf & 1 & 2 & 6 & 8 & 0.544 \\
\hline Rel & $1 / 2$ & 1 & 4 & 5 & 0.309 \\
\hline Serv & $1 / 6$ & $1 / 4$ & 1 & 1 & 0.079 \\
\hline CoM & $1 / 8$ & $1 / 5$ & 1 & 1 & 0.069 \\
\hline & \multicolumn{2}{|c|}{$\lambda_{\max }=4.018$} & $C I=0.005$ & $C R=0.006$ & \\
\hline $\begin{array}{l}\text { Table 3- With respect to the } \\
\text { tolerances }\end{array}$ & \multicolumn{2}{|c|}{ Used RM } & Tolerances & Consumption & Weights \\
\hline Used RM & \multicolumn{2}{|c|}{1} & $1 / 8$ & $1 / 9$ & 0.054 \\
\hline Tolerances & \multicolumn{2}{|c|}{8} & 1 & $1 / 2$ & 0.357 \\
\hline Consumption & \multicolumn{2}{|c|}{9} & 2 & 1 & 0.589 \\
\hline
\end{tabular}

If the consistency ratio (CR) of a table is below 0.1 , the table is rejected the comparisons should be repeated or improved. The Weights columns of the tables are to build the below matrices.

$$
\begin{aligned}
& \text { Perf Rel Serv Noises } \\
& \text { Pro \& Tech }\left[\begin{array}{llll}
0.100 & 0.648 & 0.053 & 0
\end{array}\right. \\
& W_{2}=\begin{array}{l}
\text { Used } R M \\
\text { Tolerances } \\
\quad \text { Consumption }
\end{array}\left[\begin{array}{cccc}
0.900 & 0.122 & 0.474 & 0 \\
0 & 0.230 & 0 & 0.250 \\
0 & 0 & 0.474 & 0.750
\end{array}\right]
\end{aligned}
$$

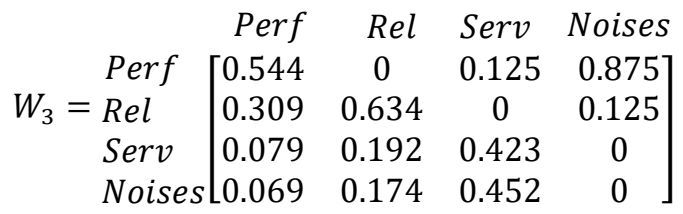

$$
\begin{aligned}
& \text { P\&T Used RM Toler Cons } \\
& W_{4}=\begin{array}{l}
\text { Pro \& Tech } \\
\text { Used RM } \\
\text { Tolerances } \\
\text { Consumption }
\end{array}\left[\begin{array}{cccc}
0.833 & 0.238 & 0 & 0.191 \\
0.167 & 0.428 & 0.054 & 0.467 \\
0 & 0.269 & 0.357 & 0.171 \\
0 & 0.065 & 0.589 & 0.171
\end{array}\right]
\end{aligned}
$$

The states for applying a Markov chain can be defined as: $\mathrm{S}=[\operatorname{Perf}, \operatorname{Rel}, \operatorname{Serv}$, Noises $]$. The probabilities for the transition matrix are found with regard to the historical data adjusted by some inputs coming from decision makers. The first row of matrix $P$ shows that if the current state of customers is the performance, the probability of remaining at the performance state is 0.19 and the probabilities of moving to states of the reliability, serviceability,

\begin{tabular}{|c|c|c|c|c|}
\hline & Perf & Rel & Serv & Noises \\
\hline Per & $\lceil 0.19$ & 0.3 & 0.22 & 0.2 \\
\hline & 0 . & 0.20 & 0.48 & \\
\hline & 0.55 & 0.21 & 0.22 & 0.0 \\
\hline & 0.3 & 0.18 & 0.09 & 0.4 \\
\hline
\end{tabular}
and cost of maintenance are $0.3,0.22$, and 0.29 . In this study, having a good source of customer previous data is essential because only based on historical data of customers' behavior and reactions, computing these probabilities becomes possible.

The CNs are affected by this matrix. At $t_{0}, t_{1}, t_{2}, t_{3}, \ldots$ the results are as follows. 


\begin{tabular}{|c|c|c|c|}
\hline $\begin{array}{ll} & \text { Perf } \\
& (0)^{T}\end{array}$ & Rel & Serv & Noises \\
\hline$W_{1}^{(0)^{I}}=[0.667$ & & 0.200 & $0.100]$ \\
\hline$W_{1}^{(1)^{T}}=[0.267$ & 0.267 & 0.216 & $0.250]$ \\
\hline$W_{1}^{(2)^{T}}=[0.250$ & 0.224 & 0.257 & $0.269]$ \\
\hline$W_{1}^{(3)^{T}}=[0.274$ & 0.222 & 0.243 & $0.261]$ \\
\hline$W_{1}^{(i)^{T}}=[0.269$ & 0.224 & 0.244 & $0.263]$ \\
\hline
\end{tabular}

The proposed Markovian-ANP-QFD is providing the decision maker with a series of the CNs to be replaced with the original one, but as mentioned earlier, it doesn't make sense to compute the $W_{A N P}$ for each $W_{1}^{(i)^{T}}$. Defining discrete time as the moments that customers are buying the product is very restrictive and even if it is possible, very soon and after few transitions, the Markov chain, because of its inherent convergence, produces the same $W_{1}^{(i)^{T}}$. This resulted matrix (or the pattern) doesn't depend on the values in $W_{1}$. So, the changing matrix of the CNs, $W_{1}^{(i)^{T}}$, becomes the same, here, when i is greater than 4. It only depends on the transition matrix and is used instead of $W_{1}$. Therefore, $W_{A N P}$ is resulted independent of the instant priorities of the customer needs as it is presented below.

$$
W_{\text {ANP }}=\begin{gathered}
\text { Pro \& Tech } \\
\text { Used RM } \\
\text { Tolerances } \\
\text { Consumption }
\end{gathered}\left[\begin{array}{l}
0.333 \\
0.341 \\
0.200 \\
0.126
\end{array}\right]
$$

Based on $W_{A N P}$, the "used raw materials for the Pumps" is the most important product requirement to improve and the "consumption" is the least important one. This matrix is used to determine the priority of the PRs for the purpose of assigning the resources in improvement process to achieve a higher level of customer satisfaction.

\section{5- Discussion}

One of the unique characteristics of QFD is its capability to translate the CNs priority to the PRs priority (Kuijt et al., 2009). The problem in traditional forms of QFD was the inability to include the inner relations between the elements. To let all the relations between the elements regardless of their hierarchy be considered, the ANP-QFD, as a generalization of the AHP-QFD, was developed (Kamvysi et al., 2010). After finding the PRs, a prioritized list of the needs, and the inner and outer relations of them, it seems easy to find the priority vector of the PRs. To deal with the high-level of subjectivity in acquiring the CNs, several researchers are proposing various methods, but only a few studies deal with the fact of possible changes in the priorities of the CNs. In fact, applying tools and techniques to increase the level of accuracy of obtaining the instant priorities of the CNs is not making sense, unless the possible changes in them are already taken into account. A paper Raharjo et al. (2010) focus on tracing changes in the CNs. A distance forecasting approach is applied in that study to trace the future CNs. They deal with the future $\mathrm{CNs}$ at the moment of sending the products to the market based on the current CNs. Asadabadi (2014) highlights the fact that the CNs are continuously changing and they should be replaced with a sequence of the CNs, but the proposed approach doesn't suggest a sufficient method to obtain such a sequence.

According to Yahia (2010): "The structure of the QFD models was strengthened by integrating different traditional techniques and approaches such as total quality management (TQM), the theory of solving inventive problems (TRIZ), failure mode and effects analysis (FMEA), the analytical hierarchy process (AHP), the analytical network process (ANP), the technique for order preference by similarity to ideal solution (TOPSIS), and artificial intelligence", but an effective application of a method to trace changes in priorities of the CNs and to find a pattern to create an approach independent of those changes was not suggested previously. A Markov chain was previously applied by Wu and Shieh (2008) to strengthen the QFD method, but their approach is to predict the relations in QFD rather than tracing the CNs. In the study by Wu and Shieh (2008), relations between the PRs and CNs are assumed to have four statuses: strong $(\mathrm{S})$, medium $(\mathrm{M})$, weak $(\mathrm{W})$, and none $(\mathrm{N})$.; "As we start the improvement process, it takes time to improve the product and send it to the market, so it would be of interest to trace the future trends.

To cite this document: Mehdi Rajabi Asadabadi, (2016) "A Markovian-QFD approach in addressing the changing priorities of the customer needs", International Journal of Quality \& Reliability Management, Vol. 33 Issue: 8, pp.1062-1075, https://doi.org/10.1108/IJQRM-07-20140091 
Under such circumstances, Markov chains model could be an approach to model from probabilities viewpoints and model the relations among the elements." (Wu \& Shieh, 2008)

The problem of possible changes in the priority of the CNs is less seen in the previous studies while it is addressed by this paper through an application of a Markov chain. In the previous applications, a receiver to evaluate CNs is not considered, but as it is illustrated in this methodology, the ANP-QFD is equipped with a Markov chain for that purpose. This chain receives the first set of the CNs as $W_{1}$, then it starts creating the next sets of CNs which are shown by $W_{1}^{k}$, where $\mathrm{k}$ is the $\mathrm{k}^{\text {th }}$ set of the CNs. But, as the methodology is followed, it is realized that by increasing $\mathrm{k}$ the approach is producing the same priority of $\mathrm{CNs}$ which is interestingly independent of the initial and changing priorities of them. Considering the study of Wu and Shieh (2008) focusing on the relations in the QFD methodology, this paper attaches a Markov chain to the entrance of an ANP-QFD approach to evaluate the CNs. While the ANPQFD is dealing with the translation process, a Markov chain is in charge of creating a pattern for the CNs priorities.

Considering the rapid changes in the market, as mentioned frequently in applications of the modern QFD approach, this methodology introduces a new framework to deal with the changing priorities of the customer needs. This happens by finding a pattern for them independent of their initial priorities which save decision makers from frequent referring to the customers to know about their desires and preferences. This methodology unlike its appearance is not very time consuming. All the methodology can be designed software-based by applying, e.g., MS Excel. Determining the relations among the CNs, PRs and between them takes time only for the first time of setting up and applying the software. Then only a review on the relations every few months (depending on the market and product) is acceptably adequate. Due to the internal calculations and multiplications of the methodology, small changes in some numbers almost have no influences on the results and this defines the Markovian-ANP-QFD method as a robust approach which is not affected by small judgemental errors.

This paper creates following areas worthy for future studies. First, there is an area of research addressing the problem of changing the other elements of QFD as well as the internal relations between them. Second, limitation in resources can be involved to develop a new model through an approach combining Markovian-ANP-QFD and goal programming.

\section{Conclusion}

The CNs are based on customers preferences and traditionally are resulted directly from interviews and meetings with customers. Accuracy in obtaining the CNs plays an important role in finding the priority of the PRs, but it makes sense only when possible changes of the CNs are taken into account before attempting to increase the accuracy of the initial CNs . Tracing the CNs is a less studied problem in the previous studies. In this paper, a Markov chain was employed to receive, evaluate, and trace the CNs and it was attached to the entrance of an ANPQFD model. It was realized that the model can be developed independent of the initial CNs which are continuously changing. This allows the decision makers to save time and focus on the accuracy of the model to find the priority of the PRs to improve rather than take their time to acquire frequently the initial CNs. The applied QFD was observant to all the inner and outer relations among the elements. Therefore, After the Markov chain evaluates the priorities of the CNs and finds the pattern of the CNs priority, QFD receives the pattern and then considering the inner and outer relations of the elements, it determines the priority vectors of the PRs. The integration of a Markov chain and ANPQFD develops the previous models and creates a stable and robust tool for the product improvement process. Considering the previous studies, the contribution of this paper is as follows. It attaches Markov chains to the entrance of an ANP-QFD to make a stochastic ANP-QFD. It traces the CNs of QFD and finds the pattern of the CNs to calculate the priority vectors of the PRs independent of the traditional instant priorities of the CNs. Although the ANP-QFD has been increasingly applied recently, there are almost no papers addressing or tracing properly the changes of the CNs in the ANP-QFD model.

\section{Acknowledgement}

\section{References}

Asadabadi, M. R. (2014). A hybrid QFD-based approach in addressing supplier selection problem in product improvement process. . International Journal of Industrial Engineering Computations, 5(4), 543-560.

To cite this document: Mehdi Rajabi Asadabadi, (2016) "A Markovian-QFD approach in addressing the changing priorities of the customer needs", International Journal of Quality \& Reliability Management, Vol. 33 Issue: 8, pp.1062-1075, https://doi.org/10.1108/IJQRM-07-20140091 
Andronikidis, A., Georgiou, A. C., Gotzamani, K., \& Kamvysi, K. (2009). The application of quality function deployment in service quality management. TQM Journal, 21(4), 319-333.

Ayağ, Z., Samanlioglu, F., \& Büyüközkan, G. (2013). A fuzzy QFD approach to determine supply chain management strategies in the dairy industry. Journal of Intelligent Manufacturing, 24(6), 1111-1122.

Baramichai, M., Zimmers,Emory W.,Jr, \& Marangos, C. A. (2007). Agile supply chain transformation matrix: An integrated tool for creating an agile enterprise. Supply Chain Management, 12(5), 334

Büyüközkan, G., \& Berkol, Ç. (2011). Designing a sustainable supply chain using an integrated analytic network process and goal programming approach in quality function deployment. Expert Systems with Applications, 38(11), 13731-13748.

Castellano, R., \& Scaccia, L. (2014). Can CDS indexes signal future turmoils in the stock market? A markov switching perspective. Central European Journal of Operations Research, 22(2), 285-305.

Cheng, C., Chiu, S. W., Cheng, C., \& Wu, J. (2012). Customer lifetime value prediction by a markov chain based data mining model: Application to an auto repair and maintenance company in Taiwan. Scientia Iranica.Transaction E, Industrial Engineering, 19(3), 849-855.

Delice, E. K., \& Güngör, Z. (2009). A new mixed integer linear programming model for product development using quality function deployment. Computers \& Industrial Engineering, 57(3), 906-912.

Dey, S., Kumar, A., Ray, A., \& Pradhan, B. B. (2012). Supplier Selection: Integrated Theory using DEMATEL and Quality Function Deployment Methodology. Procedia Engineering, 38, 3560-3565.

Ginn, D., \& Zairi, M. (2005). Best practice QFD application: an internal/external benchmarking approach based on Ford Motors' experience. International Journal of Quality \& Reliability Management, 22(1), 38-58.

Gowid, S., Dixon, R., \& Ghani, S. (2014). Optimization of reliability and maintenance of liquefaction system on FLNG terminals using markov modelling. The International Journal of Quality \& Reliability Management, 31(3), 293-310.

Hauster, J.R., \& Clausing, D. (1988), the house of quality, Harvard business review, 66(3), 63-73

Ho, W., Dey, P. K., \& Lockström, M. (2011). Strategic sourcing: A combined QFD and AHP approach in manufacturing. Supply Chain Management, 16(6), 446-461.

Iqbal, Z., Grigg, N. P., Govinderaju, K., \& Campbell-Allen, N. (2014). Statistical comparison of final weight scores in quality function deployment (QFD) studies. The International Journal of Quality \& Reliability Management, 31(2), 184-204.

Kamvysi, K., Gotzamani, K., Georgiou, A. C., \& Andronikidis, A. (2010). Integrating DEAHP and DEANP into the quality function deployment. TQM Journal, 22(3), 293-316.

Karsak, E. E., Sozer, S., \& Alptekin, S. E. (2003). Product planning in quality function deployment using a combined analytic network process and goal programming approach. Computers \& industrial engineering, 44(1), 171-190.

Kuijt-Evers, L., Morel, K., Eikelenberg, N., \& Vink, P. (2009). Application of the QFD as a design approach to ensure comfort in using hand tools: Can the design team complete the house of quality appropriately? Applied Ergonomics, 40(3), 519.

Kutschenreiter-praszkiewicz, I. (2013). Application of neural network in QFD matrix. Journal of Intelligent Manufacturing,24(2), 397-404.

Lin, Y., \& Pekkarinen, S. (2011). QFD-based modular logistics service design.Journal of Business \& Industrial Marketing, 26(5), 344-356. Andronikidis, A., Georgiou, A. C., Gotzamani, K., \& Kamvysi, K. (2009). The application of quality function deployment in service quality management. The TQM journal, 21(4), 319-333.

Lin, Y., Cheng, H. P., Tseng, M. L., \& Tsai, J. C. (2010). Using QFD and ANP to analyze the environmental production requirements in linguistic preferences.Expert Systems with Applications, 37(3), 2186-2196.

Liu, C. H., Chiu, C. L., \& Chiu, S. C. (2011). Analyze dynamic value of strategic partners using Markov chain. Expert Systems with Applications, 38(11), 13563-13567.

Mazur, G.H. (2008), Delighting customers with quality function deployment: voice of customers meets voice of process. 14th international symposium on QFD.

Partovi, F. Y. (2007). An analytical model of process choice in the chemical industry. International Journal of Production Economics, 105(1), 213-227.

Partovi, F.Y. (2001). An analytic model to quantify strategic service vision. International Journal of Service Industry Management, Vol. 12, pp. 476-99.

Ozdağoğlu, G., \& Salum, L. (2009). Modern QFD-based requirements analysis for enterprise modelling: enterpriseQFD. International Journal of Computer Integrated Manufacturing, 22(12), 1102-1127.

Raharjo, H., Brombacher, A. C., \& Xie, M. (2008). Dealing with subjectivity in early product design phase: A systematic approach to exploit quality function deployment potentials. Computers \& Industrial Engineering, 55(1), 253.

Raharjo, H., Xie, M., \& Brombacher, A. C. (2011). A systematic methodology to deal with the dynamics of customer needs in Quality Function Deployment.Expert Systems with Applications, 38(4), 3653-3662.

Raharjo, H., Xie, M., Goh, T. N., \& Brombacher, A. C. (2007). A methodology to improve higher education quality using the quality function deployment and analytic hierarchy process. Total Quality Management \& Business Excellence, $18(10), 1097$.

Rika Fatimah, ,P.L. (2014). The development of FFMD pyramid: Fuzzy Family_Marriage deployment as decision support method to improve human resources performance. Quality and Quantity, 48(2), 659-672.

Saaty, T. L. (1986). Axiomatic foundation of the analytic hierarchy process. Management science, 32(7), 841-855.

Saaty, T. L. (1990). How to make a decision: the analytic hierarchy process. European journal of operational research, 48(1), 926.

Saaty, T. L. (1999). Fundamental of the Analytic Network Process, ISAHP, Kobe, Japan, August 12-14. using quality function deployment .Computer and Industrial Engineering. 57. 907-912.

To cite this document: Mehdi Rajabi Asadabadi, (2016) "A Markovian-QFD approach in addressing the changing priorities of the customer needs", International Journal of Quality \& Reliability Management, Vol. 33 Issue: 8, pp.1062-1075, https://doi.org/10.1108/IJQRM-07-20140091 
Saibeni, A. A. (2010). Forecasting accounts receivable collections with Markov chains and Microsoft excel. The CPA Journal,80(4), 66-71.

Shen, X. X., Xie, M., \& Tan, K. C. (2001). Listening to the future voice of the customer using fuzzy trend analysis in QFD. Quality Engineering, 13(3), 419-425.

Shieh, J., \& Wu, H. (2009). Applying a hidden markov chain model in quality function deployment to analyze dynamic customer requirements. Quality and Quantity, 43(4), 635-644.

Steiner, F., Tarman, R. T., Ihl, J. C., \& Piller, F. T. (2009, August). Learning from the customer: Identifying changing user needs during product usage through embedded toolkits for user innovation. In Management of Engineering \& Technology, 2009. PICMET 2009. Portland International Conference on (pp. 706-716). IEEE.

Sullivan, L.P. (1986), “Quality function deployment”, Quality Progress, Vol. 19 No. 6, pp. 39-50.

Wong, J. K., \& Li, H. (2008). Application of the analytic hierarchy process (AHP) in multi-criteria analysis of the selection of intelligent building systems.Building and Environment, 43(1), 108-125.

Wu, H. H., Liao, A. Y. H., \& Wang, P. C. (2005). Using grey theory in quality function deployment to analyse dynamic customer requirements. The International Journal of Advanced Manufacturing Technology, 25(11-12), 1241-1247.

Wu, H., \& Shieh, J. (2008). Applying a markov chain model in quality function deployment. Quality and Quantity, 42(5), 665678.

Yahia, Z. M. (2010). Quality function deployment and its extensions. The International Journal of Quality \& Reliability Management, 27(6), 616-640.

Yang, C. L., Chuang, S. P., \& Huang, R. H. (2009). Manufacturing evaluation system based on AHP/ANP approach for wafer fabricating industry. Expert Systems with Applications, 36(8), 11369-11377.

Zultner, R. E. (1995). Software QFD: The North American Experience. In Proceedings of the 1st Pacific Rim Symposium on Quality Deployment (pp. 163-174).

Zultner, R. E. (2005). The essential role of QFD in design for six sigma: modern QFD for modern TQM. In Transactions from the 17th Symposium on QFD (pp. 73-85). QFD Institute.

To cite this document: Mehdi Rajabi Asadabadi, (2016) "A Markovian-QFD approach in addressing the changing priorities of the customer needs", International Journal of Quality \& Reliability Management, Vol. 33 Issue: 8, pp.1062-1075, https://doi.org/10.1108/IJQRM-07-20140091 